\title{
RF Phase Stability and Electron Beam Characterization for the PLEIADES Thomson X-ray Source
}

W. J. Brown, F. V. Hartemann, A. M. Tremaine, P. T. Springer, G. P. Le Sage, C.P.J. Barty, J. B. Rosenzweig, J. K. Crane, R. R. Cross, D. N. Fittinghoff, D. J. Gibson, D.R. Slaughter, S. Anderson

This article was submitted to the International Conference on Infrared and Millimeter Waves; San Diego, CA; September 22-26, 2002

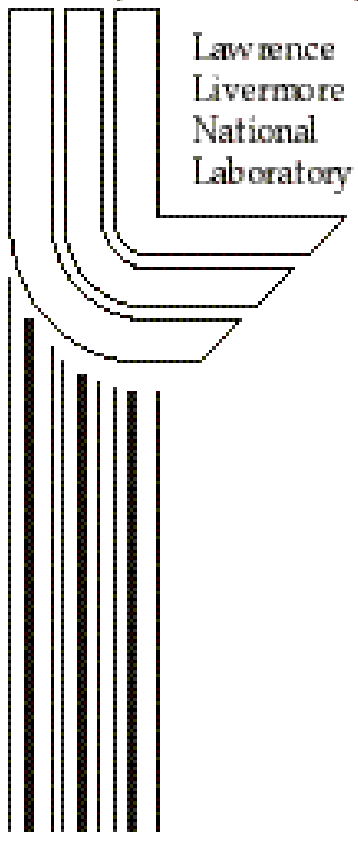

\section{October 16, 2002}




\section{DISCLAIMER}

This document was prepared as an account of work sponsored by an agency of the United States Government. Neither the United States Government nor the University of California nor any of their employees, makes any warranty, express or implied, or assumes any legal liability or responsibility for the accuracy, completeness, or usefulness of any information, apparatus, product, or process disclosed, or represents that its use would not infringe privately owned rights. Reference herein to any specific commercial product, process, or service by trade name, trademark, manufacturer, or otherwise, does not necessarily constitute or imply its endorsement, recommendation, or favoring by the United States Government or the University of California. The views and opinions of authors expressed herein do not necessarily state or reflect those of the United States Government or the University of California, and shall not be used for advertising or product endorsement purposes.

This is a preprint of a paper intended for publication in a journal or proceedings. Since changes may be made before publication, this preprint is made available with the understanding that it will not be cited or reproduced without the permission of the author. 


\section{RF Phase Stability and Electron Beam Characterization for the PLEIADES Thomson X-ray Source}

W. J. Brown ${ }^{1}$, F. V. Hartemann ${ }^{1}$, A. M. Tremaine ${ }^{1}$, P. T. Springer ${ }^{1}$, G. P. Le Sage ${ }^{1}$, C.P.J. Barty ${ }^{1}$, J. B. Rosenzweig ${ }^{2}$, J. K. Crane ${ }^{1}$, R. R. Cross ${ }^{1}$, D. N. Fittinghoff ${ }^{1}$, D. J. Gibson ${ }^{3}$, D.R. Slaughter ${ }^{1}$, S. Anderson ${ }^{2}$

${ }^{1}$ Lawrence Livermore National Laboratory, 7000 East Ave., Livermore, CA. 94550

${ }^{2}$ UCLA Department of Physics and Astronomy, 405 Hilgard Ave, Los Angeles, CA. 90095

${ }^{3}$ UCD Department of Applied Science, 661 Hertz Hall, Livermore, CA, 94550

\begin{abstract}
We report on the performance of an Sband RF photocathode electron gun and accelerator for operation with the PLEIADES Thomson x-ray source at LLNL. To produce picosecond, high brightness x-ray pulses, picosecond timing, terahertz bandwidth diagnostics, and RF phase control are required. Planned optical, RF, x-ray and electron beam measurements to characterize the dependence of electron beam parameters and synchronization on RF phase stability are presented.
\end{abstract}

\section{INTRODUCTION}

PLEIADES (Picosecond Laser Electron InterAction for Dynamic Evaluation of Structures) is a next generation Thomson scattering $\mathrm{x}$-ray source being developed at Lawrence Livermore National Laboratory (LLNL). Ultra-fast ps x-rays (10-200 $\mathrm{keV})$ are generated by colliding an energetic electron beam (20-100 MeV) with a high intensity, sub-ps, $800 \mathrm{~nm}$ laser pulse. Generation of sub-ps pulses of hard $\mathrm{x}$-rays $(30 \mathrm{keV})$ has previously been demonstrated at the LBNL Advanced Light Source injector linac, with $\mathrm{x}$-ray beam fluxes of $10^{5}$ photons per pulse [1]. The LLNL source is expected to achieve fluxes between $10^{7}-10^{8}$ photons for pulse durations of 100 fs to 5 ps using interaction geometries ranging from $90^{\circ}$ (side-on collision) to $180^{\circ}$ (head-on collision).

\section{EXPERIMENT LAYOUT}

The PLEIADES facility consists of a Ti-Sapphire OPCPA laser system capable of producing bandwidth limited laser pulses of $50 \mathrm{fs}$ with up to 1 joule of energy at $800 \mathrm{~nm}$, an S-band photo-cathode RF gun, and a $100 \mathrm{MeV}$ linac consisting of 4, 2.5-meter-long accelerator sections. The RF gun is driven by a picosecond, $1 \mathrm{~mJ}$, UV laser that is synchronized to the interaction drive laser.

A schematic of the interaction region is shown in Figure 1. To maximize $\mathrm{x}$-ray flux while minimizing effects of timing jitter, the laser incidence angle will initially be 180 degrees with respect to electron beam direction, though a 90 degree interaction geometry will also be possible. The focal length between the final focus quadrupole triplet and the interaction region is $10 \mathrm{~cm}$ to allow for maximum focus strength and minimum electron bunch spot size. A 30-degree bend dipole magnet will be used to bend the electron bunch out of the x-ray beam path following the interaction. An off-axis $1.5 \mathrm{~m}$ focal length, parabolic mirror will be used to focus the laser to a diffraction-limited $15 \mu \mathrm{m}$ FWHM spot size at the interaction point. A beryllium flat mirror placed in the X-ray beam path will serve as the final steering optic for the laser, while being transparent to the $\mathrm{x}$-ray beam.

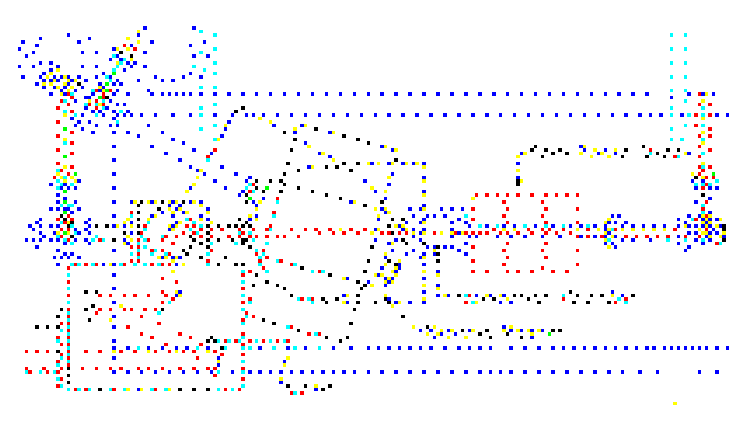

Figure 1: Interaction geometry

\section{ELECTRON BEAM PRODUCTION}

Initial experiments will focus on the generation of 30 $\mathrm{keV} \mathrm{x}$-rays produced in a head on collision using a 35 $\mathrm{MeV}$ electron beam. Simulations have been performed using PARMELA to optimize the beam production and transport. It has been shown that by injecting the $0.5 \mathrm{nC}, 5 \mathrm{MeV}$ electron beam produced by the RF gun into the first accelerating section sufficiently ahead of the peak accelerating phase, the bunch can be substantially compressed in time, from about 6 ps FHWM to about 1.7 ps FWHM. The subsequent accelerator sections can then be used to accelerate the beam to $35 \mathrm{MeV}$ as well as remove some of the energy spread induced during the compression process. At the exit of the accelerator, the electron beam normalized rms emittance is about 
$3.5 \pi \mathrm{mm}$-mrad, the rms bunch length is $0.7 \mathrm{ps}$, and the rms energy spread is $0.5 \%$. A spot size of $30 \mu \mathrm{m}$ FWHM is obtained at the focus.

\section{X-RAY PULSE PRODUCTION AND TIMING JITTER EFFECTS}

The expected $\mathrm{x}$-ray production was calculated and the effects of RF phase and timing jitter were determined by integrating the emissions probability per unit time, $d N_{x} / d t$, given by

where $n_{\gamma}(\mathbf{x}, t)$ is the laser photon density, and $n_{e}(\mathbf{x}, t)$ is the electron density. The calculations were performed with a $300 \mathrm{~mJ}, 300$ fs laser pulse in conjunction with the PARMELA output in place of $n_{e}(\mathbf{x}, t)$. Figure 2 shows the expected x-ray yield versus phase jitter of the linac for the cases where the electron beam is compressed in the first section (accelerated near the zero crossing), and not compressed (accelerated on crest).

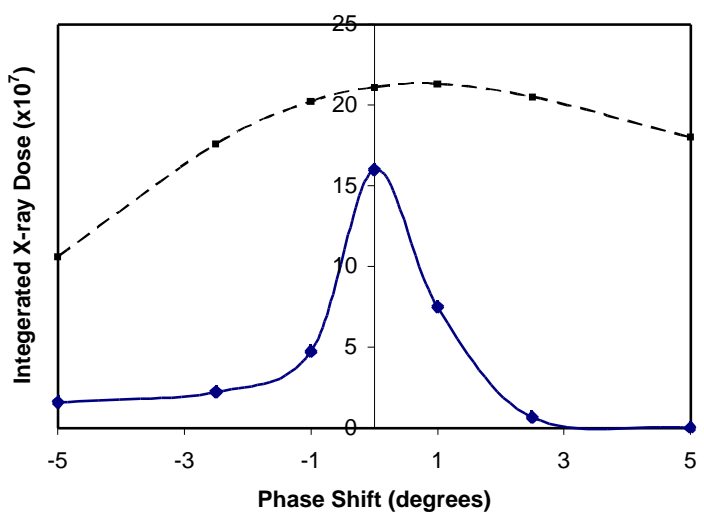

Figure 2: Simulated x-ray yield versus phase shift (Dotted: compressed beam. Solid: uncompressed).

It is seen that the phase jitter requirements for the compressed beam is less than one degree (or about 1 ps). Thus, picosecond phase and timing control will be required to maintain stability of the x-ray source when operated in the short bunch mode.

\section{BEAM CHARACTERIZATION}

To date, the electron beam has been accelerated up to $60 \mathrm{MeV}$, and the emittance for a $300 \mathrm{pC}$ bunch has been measured to be about $15 \pi \mathrm{mm}$-mrad. Improvements in emittance are expected with improvements in the UV drive laser uniformity and optimization of the electron beam transport. Phase jitter between the drive laser oscillator and the RF phase in the gun has been measured by mixing a 2.8 $\mathrm{GHz}$ microwave signal generated by the laser oscillator with the fields taken directly from the RF gun. This has shown short time scale $(<1$ minute $)$ phase stability of \pm 1 degree.

Longer term phase drifts will be eliminated by a computer controlled feed back loop integrated with a direct measurement of the UV drive laser arrival phase in the RF gun and a voltage controlled phase shifter used to implement phase corrections. The direct phase measurement will employ a $20 \mathrm{GHz}$ bandwidth, $800 \mathrm{~nm}$ optical fiber switch modulated by microwaves sampled from the RF gun to provide a nonlinear correlation between the gun fields and the IR laser pulse used to produce the UV photocathode drive laser.

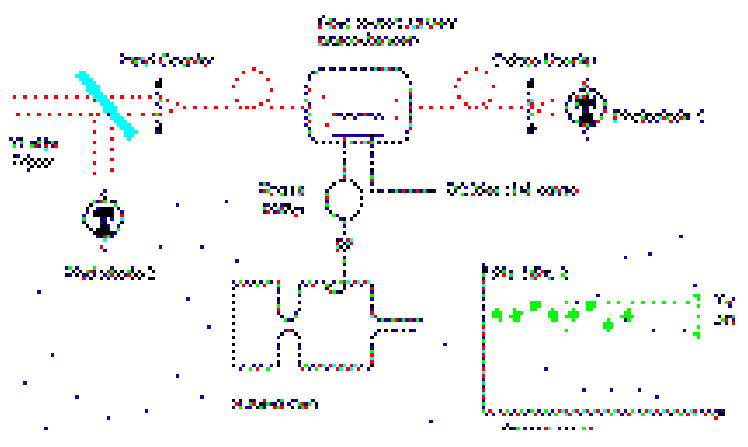

Figure 3: Direct phase jitter measurement.

\section{CONCLUSIONS}

The PLEIADES Thomson $\mathrm{x}$-ray source facility will provide high brightness (> $10^{7} \mathrm{x}$-rays/pulse), picosecond pulses for dynamic measurements in matter, including radiography, dynamic diffraction, and spectroscopy. Careful diagnosis and control of $\mathrm{RF}$ jitter and laser to RF timing will be required to produce stable picosecond to sub-picosecond x-ray pulses. Expected performance parameters and planned jitter measurements and control methods have been presented

\section{ACKNOWLEDGEMENTS}

This work was performed under the auspices of the U.S. Department of Energy by the University of California, Lawrence Livermore National Laboratory under contract No. W-7405-Eng-48.

\section{REFERENCES}

[1] R.W. Schoelein, et. al., "Femtosecond x-ray pulses at 0.4 Angstrom generated by 90 degrees Thomson scattering: A tool for probing structural dynamics of materials," Science 274, 236 (1996). 